\title{
Long-Term Tocolysis With Magnesium Sulfate as a Risk Factor for Low Bone Mass: A Case Series
}

\author{
Kazuaki Iio ${ }^{a}$, Emi Kondo a, b, Eiji Shibata a , Tamaki Wada ${ }^{a}$, Takayuki Uchimura ${ }^{a}$, \\ Yasuyuki Kinjo ${ }^{\text {a }}$, Midori Murakami ${ }^{\text {a }}$, Kiyoshi Yoshino ${ }^{a}$
}

\begin{abstract}
Pregnancy and lactation-associated osteoporosis (PLO) is a disease caused by vertebral compression fracture, and it is characterized by low back pain during pregnancy or the postpartum period. However, it is difficult to predict and prevent PLO prepartum in highrisk groups. Recently, long-term tocolysis with magnesium sulfate $\left(\mathrm{MgSO}_{4}\right)$ has been reported to be associated with PLO. The purpose of this case series was to assess postpartum bone mass after long-term tocolysis with $\mathrm{MgSO}_{4}$ and accumulated doses of $\mathrm{MgSO}_{4}$. We report the case of a pregnant woman with vertebral compression fractures during pregnancy following long-term tocolysis with $\mathrm{MgSO}_{4}$. We investigated whether long-term tocolysis with $\mathrm{MgSO}_{4}$ was a high risk factor for PLO. Therefore, we retrospectively evaluated bone mineral density after delivery in nine women who had long-term tocolysis with $\mathrm{MgSO}_{4}$ (more than 8 days) for treatment of threatened preterm birth at our hospital from January 2020 to December 2020. The age of the women was between 20 and 41 years (mean age, 30 years). The body mass index of the women was between 18.1 and $25.4 \mathrm{~kg} /$ $\mathrm{m}^{2}$ (mean $20.0 \mathrm{~kg} / \mathrm{m}^{2}$ ). Three women had a positive smoking history, and none had a family history of osteoporosis. The average duration of tocolysis with $\mathrm{MgSO}_{4}$ was 11 - 97 days. The accumulated doses of $\mathrm{MgSO}_{4}$ were between 168 and 3,756 g. Four of nine cases were diagnosed with low bone mass of young adult mean (YAM) value $\leq 80 \%$. Of them, one case (accumulated doses of $\mathrm{MgSO}_{4}: 1,260 \mathrm{~g}$ ) was diagnosed with PLO of YAM value $\leq 70 \%$, and one case (accumulated doses of $\mathrm{MgSO}_{4}: 3,756 \mathrm{~g}$ ) was diagnosed with bone fracture with a YAM value of $\leq 70 \%$. Long-term tocolysis with $\mathrm{MgSO}_{4}$ may be suggested as one of the risk factors of PLO. Nutritional guidance and rehabilitation are important interventions for target patients.
\end{abstract}

Keywords: Tocolysis; Magnesium sulfate; Low bone mass; Pregnancy and lactation-associated osteoporosis

Manuscript submitted November 4, 2021, accepted December 2, 2021

Published online February 16, 2022

aDepartment of Obstetrics and Gynecology, University of Occupational and Environmental Health, 1-1 Iseigaoka, Yahatanishi-ku, Kitakyushu, Fukuoka 857-8556, Japan

${ }^{\mathrm{b} C}$ Corresponding Author: Emi Kondo, Department of Obstetrics and Gynecology, University of Occupational and Environmental Health, 1-1 Iseigaoka, Yahatanishi-ku, Kitakyushu, Fukuoka 857-8556, Japan.

Email: ek89224@med.uoeh-u.ac.jp

doi: https://doi.org/10.14740/jmc3833

\section{Introduction}

Bone mineral density during pregnancy is normally mildly reduced or unchanged [1]. Moreover, lactation is reported to cause a transient loss of 3-9\% of bone mineral density due to increased bone resorption and loss of large amounts of calcium [2]. During pregnancy, about $30 \mathrm{~g}$ of calcium is transferred to the fetus, and about $300-400 \mathrm{mg}$ is lost per day during the postpartum period through breastfeeding [3]. In breastfeeding, elevated prolactin reduces estrogen levels and increases the secretion of parathyroid hormone-related protein (PTHrP); therefore, bone mineral is reduced [4]. Pregnancy and lactation-associated osteoporosis (PLO) is a rare disease that occurs during pregnancy or postpartum period, presenting with back pain and vertebral bone fracture [5]. It is described as a primary osteoporosis that causes lumbar back pain and vertebral compression fracture during pregnancy or postpartum period and significantly reduces the quality of life [6]. The pathogenesis of PLO was first reported in 1955 [7]. There is no clear definition of PLO; however, it is generally diagnosed according to the criteria for diagnosis of primary osteoporosis [8]. The risk factors for PLO are low body weight, a family history of fragility fracture/osteoporosis, vitamin D insufficiency, and smoking [9]. Long-term tocolysis with magnesium sulfate $\left(\mathrm{MgSO}_{4}\right)$ has been reported to affect maternal calcium metabolism and cause a decrease in bone mineral density [10]. We report a case of PLO after long-term tocolysis with $\mathrm{MgSO}_{4}$ for preterm birth. We performed a bone mineral density test in this case (dual-energy X-ray absorptiometry (DEXA)) in the postpartum period for patients who had long-term tocolysis with $\mathrm{MgSO}_{4}$. We investigated the relationship between longterm tocolysis with $\mathrm{MgSO}_{4}$ during pregnancy and bone mineral density with a literature discussion.

\section{Case Report}

\section{Investigations}

A 36-year-old Japanese woman, gravida 2, para 1, was transferred to our hospital for threatened preterm birth at 22 weeks of gestation. There were no significant medical or family histories. Her cervical length was $27 \mathrm{~mm}$ on transvaginal ultrasonography. The non-stress test showed uterine contractions 

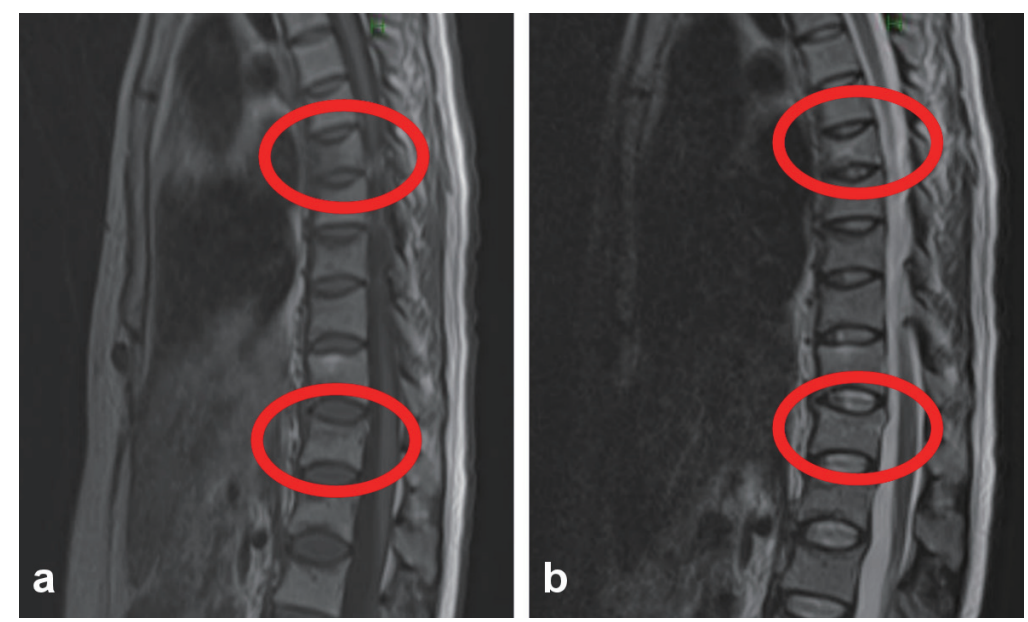

Figure 1. The anterior lumbar spine imaging sites in young adult mean (YAM) are L1 to L4. The seventh and 12th thoracic vertebrae showed T1 low signal and T2 high signal for compression fracture. (a) T1-weighted image. (b) T2-weighted image.

every 3 min with little pain. She was diagnosed with threatened preterm birth and a continuous intravenous infusion of ritodrine was started at the time of admission. At 23 weeks of gestation, she was also started on intravenous infusion of $\mathrm{MgSO}_{4}$ and received betamethasone for fetal lung maturation. Intravenous infusion of $\mathrm{MgSO}_{4}$ was maintained at a dose of 2 $\mathrm{g} / \mathrm{h}$ (accumulated dose of $\mathrm{MgSO}_{4}: 3,756 \mathrm{~g}$ ).

\section{Diagnosis}

At 35 weeks of gestation, she developed acute low back pain when she crouched over the toilet. Computed tomography (CT) from the lumbar to the pelvic region was performed to assess the cause of low back pain, and the orthopedist made a diagnosis of strained back. Because of severe back pain, pregnancy was terminated. Labor was induced, and the baby was delivered by vaginal delivery (body weight: 2,925 g, 1- and 5-min Apgar score: 8 vs. 9 points). Low back pain continued, and she underwent magnetic resonance imaging (MRI) and DEXA at 15 days after birth (Fig. 1). The seventh and 12th thoracic vertebra compression fractures were confirmed by postpartum lumbar MRI, and DEXA showed that the YAM was $67 \%$. She was diagnosed with postpartum thoracic compression fractures and osteoporosis (PLO).

\section{Treatment}

She took analgesics internally and stopped breastfeeding.

\section{Follow-up and outcomes}

It was necessary to evaluate detailed information on bone mass in a series of patients who received long-term tocolysis with $\mathrm{MgSO}_{4}$, and nine postpartum women were included in the series at our hospital from January 2020 to December 2020 (Table 1). The duration of long-term $\mathrm{MgSO}_{4}$ tocolysis was defined as $>8$ days, according to a previous report [10]. Restfulness was defined as the ability to walk in the maternity ward. Their clinical data were retrospectively analyzed (age, height,

Table 1. Nine Cases of Patients With Long-Term Tocolysis of $\mathrm{MgSO}_{4}$

\begin{tabular}{lllllllllll}
\hline No. & $\begin{array}{l}\text { Age } \\
\text { (years) }\end{array}$ & $\begin{array}{l}\text { BMI } \\
\left(\mathbf{k g} / \mathbf{m}^{2}\right)\end{array}$ & $\begin{array}{l}\text { Gravida } \\
\text { (times) }\end{array}$ & $\begin{array}{l}\text { Para } \\
\text { (times) }\end{array}$ & Prenatal smoking & $\begin{array}{l}\text { Hospitaliza- } \\
\text { tion (days) }\end{array}$ & $\begin{array}{l}\text { Use days of } \\
\mathbf{M g S O}_{\mathbf{4}} \text { (days) }\end{array}$ & $\begin{array}{l}\text { Accumulated } \\
\text { dose of } \mathbf{M g S O}_{\mathbf{4}}(\mathbf{g})\end{array}$ & $\begin{array}{l}\text { YAM } \\
(\mathbf{\%})\end{array}$ & $\begin{array}{l}\text { Bone } \\
\text { fracture }\end{array}$ \\
\hline 1 & 20 & 18.4 & 1 & 0 & - & 44 & 37 & 1,260 & 62 & - \\
\hline 2 & 36 & 22.5 & 2 & 1 & Before pregnancy & 97 & 85 & 3,756 & 67 & + \\
\hline 3 & 34 & 18.1 & 1 & 0 & - & 71 & 58 & 2,484 & 73 & - \\
4 & 27 & 20.8 & 1 & 0 & Before pregnancy & 63 & 36 & 1,464 & 75 & - \\
\hline 5 & 41 & 21.4 & 3 & 0 & - & 63 & 57 & 2,556 & 84 & - \\
6 & 30 & 20.9 & 2 & 1 & - & 28 & 13 & 336 & 87 & - \\
7 & 28 & 21.9 & 2 & 1 & - & 33 & 14 & 168 & 89 & - \\
8 & 27 & 25.4 & 1 & 0 & - & 11 & 11 & 456 & 91 & - \\
9 & 27 & 19.9 & 1 & 0 & Before pregnancy & 71 & 31 & 1,488 & 99 & - \\
\hline
\end{tabular}

BMI: body mass index; $\mathrm{MgSO}_{4}$ : magnesium sulfate; YAM: young adult mean. 
weight, body mass index (BMI), young adult mean (YAM), use days, and accumulated dose of $\left.\mathrm{MgSO}_{4}\right)$. Height $(\mathrm{cm})$ and weight $(\mathrm{kg})$ were measured on the first day of admission. BMI was calculated as $\mathrm{kg} / \mathrm{m}^{2}$. The time of examination was defined as within 1 week postpartum. The YAM was measured using dual X-ray energy absorptiometry (DXA). A YAM $<80 \%$ was defined as a low bone mineral density. Nine cases of long-term tocolysis with $\mathrm{MgSO}_{4}$ are presented in Table 1. Patients with bone mineral loss and osteoporosis with a YAM value of $<$ $80 \%$ were found in $44 \%$ of the long-term $\mathrm{MgSO}_{4}$-treated patients (four of nine cases). The average duration of $\mathrm{MgSO}_{4}$ use and the accumulated dose of $\mathrm{MgSO}_{4}$ were 38 days and 1,552 $\mathrm{g}$, respectively. The mean age of the four patients with decreased bone density was 29.3 years. The mean weight was $49.3 \mathrm{~kg}$ and the mean BMI was $20.0 \mathrm{~kg} / \mathrm{m}^{2}$. Three women had a past history of smoking, and two of the three were diagnosed with PLO. None of the patients had a family history of osteoporosis. Total accumulated dose of $\mathrm{MgSO}_{4}$ in the four low bone mass cases was more than $1,000 \mathrm{~g}$ in total. In the three cases with an accumulated dose of less than $500 \mathrm{~g}$, the bone mass was within normal limits (Table 1).

\section{Discussion}

By full-term gestation, the fetus must have acquired approximately $30 \mathrm{~g}$ of calcium, $20 \mathrm{~g}$ of phosphorus, and $0.8 \mathrm{~g}$ of magnesium to maintain normal physiological function [1]. Approximately $80 \%$ of the calcium and phosphate in the skeleton of the fetus at full-term gestation pass through the placenta in the third trimester, mostly from maternal meals during pregnancy [1]. The total calcitriol concentrations increase two- to five-fold in early pregnancy and continues to increase until delivery, but free calcitriol concentrations increase in the third trimester [11]. As a result, the absorption rate of calcium and phosphate in the intestine is twice that in non-pregnant women, and renal excretion of calcium increases [1]. In the third trimester, maternal calcium supply to the fetus begins to increase to 250 - $300 \mathrm{mg} /$ day [1].

Breast milk contains an average of $220 \mathrm{mg}$ of calcium per day in breast milk [12]. During lactation, calcium absorption in the intestine is normal, and bone metabolic turnover is increased, while bone resorption via osteoclasts and reabsorption in the kidneys are increased to supply most of the calcium in breast milk [1]. Transient resorption and demineralization of the maternal skeleton appear to be the primary mechanisms by which lactating women meet these calcium requirements [1]. This adaptation does not appear to require parathyroid hormone (PTH) or calcitriol, but is controlled by the combined effects of increased circulating concentrations of PTHrP and decreased estradiol levels [1]. During lactation, the combined effects of PTHrP (secreted by the breast) and estrogen deficiency increase skeletal resorption, reduce renal calcium losses, and raise the blood calcium, but calcium is directed into the breast milk. This decline in bone mineral density and bone strength during lactation is not inhibited by high dietary intake of calcium. The main treatment for PLO is weaning off breastfeeding. Other drug therapies such as active vitamin D, vitamin $\mathrm{K}$, bisphosphonates, and PTH preparations have been reported [2]. Bisphosphonates remain in the bones for a long time and may pass through the placenta, which may affect the fetus in the subsequent pregnancy; therefore, bisphosphonates should be used cautiously in women who wish to have a baby [13]. In recent years, PTH preparations have been used to treat PLO. The PTH preparations have a limited duration of use, and there is still the question of what to use in case of PLO in the subsequent pregnancy; first-degree [2] relatives of women with PLO have been reported to have higher fracture rates [14]. The risk factors for PLO include low body weight, low BMI, and positive smoking status. Though age, BMI, smoking and family history are risk factors for PLO, the relationship is not significant in this series [9].

Long-term tocolysis of $\mathrm{MgSO}_{4}$ has been reported to cause: 1) increased urinary calcium excretion (inhibition of reabsorption); 2) hypocalcemia due to suppression of PTH secretion; and 3) decreased bone mineral density due to 1) and 2) [15]. The specific total accumulated amount of $\mathrm{MgSO}_{4}$ that decreases bone density is not well known [15]. In this study, the total accumulated dose of $\mathrm{MgSO}_{4}$ more than 1,000 $\mathrm{g}$ was suggested to be associated with low bone mass. We propose that a cumulative dose of more than $1,000 \mathrm{~g}$ of $\mathrm{MgSO}_{4}$ is a potential risk factor for PLO. Therefore, we monitored blood and urine calcium levels in cases of long-term tocolysis of $\mathrm{MgSO}_{4}$ to prevent low bone mass during pregnancy.

It has been reported that lying in bed for more than 2 weeks can decrease bone mineral density [16]. The present study suggests that rest management in preterm births may also affect bone mineral loss. To prevent and treat PLO caused by longterm tocolysis of $\mathrm{MgSO}_{4}$, these measures are necessary: 1) bone density screening; 2) physical therapy; 3) breastfeeding abstinence; and 4) calcium and vitamin D supplementation [15].

The limitation is that the exact assessment of PLO was not clear because bone mineral density was not measured before pregnancy. It is possible that the pregnant women were conceived without obtaining peak bone mass because of potential vitamin D deficiency or maternal low body weight before pregnancy.

\section{Learning points}

In conclusion, we investigated nine cases of long-term $\mathrm{MgSO}_{4}$ tocolysis and compared bone mineral loss. Long-term tocolysis using $\mathrm{MgSO}_{4}$ may be a risk factor for PLO. Further case studies are needed to determine the role of $\mathrm{MgSO}_{4}$ in osteoporosis.

\section{Acknowledgments}

None to declare.

\section{Financial Disclosure}

None to declare. 


\section{Conflict of Interest}

None to declare.

\section{Informed Consent}

This study was approved by the Institutional Review Broad, and written informed consent was obtained from the patient.

\section{Author Contributions}

Emi Kondo and Eiji Shibata were responsible for the manuscript. Kazuaki Iio is first author, and wrote this paper. Tamaki Wada, Takayuki Uchimura, Yasuyuki Kinjo, Midori Muraka$\mathrm{mi}$, and Kiyoshi Yoshino read and approved the final version of the manuscript.

\section{Data Availability}

The authors declare that data supporting the findings of this study are available within the article.

\section{Abbreviations}

DEXA: dual-energy X-ray absorptiometry; DXA: dual X-ray energy absorptiometry; PLO: pregnancy and lactation-associated osteoporosis; PTHrP: parathyroid hormone-related protein

\section{References}

1. Kovacs CS. Calcium and bone metabolism disorders during pregnancy and lactation. Endocrinol Metab Clin North Am. 2011;40(4):795-826.

2. Choe EY, Song JE, Park KH, Seok H, Lee EJ, Lim SK, Rhee Y. Effect of teriparatide on pregnancy and lactationassociated osteoporosis with multiple vertebral fractures. J Bone Miner Metab. 2012;30(5):596-601.

3. Kovacs CS. Calcium and bone metabolism during pregnancy and lactation. J Mammary Gland Biol Neoplasia.
2005;10(2):105-118

4. Sanz-Salvador L, Garcia-Perez MA, Tarin JJ, Cano A. Bone metabolic changes during pregnancy: a period of vulnerability to osteoporosis and fracture. Eur J Endocrinol. 2015;172(2):R53-65.

5. Jia P, Wang R, Yuan J, Chen H, Bao L, Feng F, Tang H. A case of pregnancy and lactation-associated osteoporosis and a review of the literature. Arch Osteoporos. 2020;15(1):94.

6. Gehlen M, Lazarescu AD, Hinz C, Schwarz-Eywill M, Pfeifer M, Balasingam S, Maier A. Long-term outcome of patients with pregnancy and lactation-associated osteoporosis (PLO) with a particular focus on quality of life. Clin Rheumatol. 2019;38(12):3575-3583.

7. Nordin BE, Roper A. Post-pregnancy osteoporosis; a syndrome? Lancet. 1955;268(6861):431-434.

8. Osteoporosis. Japan. 2013;21(1):9-21. Available from: http://jsbmr.umin.jp/guide/pdf/g-guideline.pdf.

9. O'Sullivan SM, Grey AB, Singh R, Reid IR. Bisphosphonates in pregnancy and lactation-associated osteoporosis. Osteoporos Int. 2006;17(7):1008-1012.

10. Smith R, Phillips AJ. Osteoporosis during pregnancy and its management. Scand J Rheumatol Suppl. 1998;107:6667.

11. Bikle DD, Gee E, Halloran B, Haddad JG. Free 1,25-dihydroxyvitamin D levels in serum from normal subjects, pregnant subjects, and subjects with liver disease. J Clin Invest. 1984;74(6):1966-1971.

12. Kovacs CS. Maternal mineral and bone metabolism during pregnancy, lactation, and post-weaning recovery. Physiol Rev. 2016;96(2):449-547.

13. Polat SB, Evranos B, Aydin C, Cuhaci N, Ersoy R, Cakir B. Effective treatment of severe pregnancy and lactation-related osteoporosis with teriparatide: case report and review of the literature. Gynecol Endocrinol. 2015;31(7):522-525.

14. Dunne F, Walters B, Marshall T, Heath DA. Pregnancy associated osteoporosis. Clin Endocrinol (Oxf). 1993;39(4):487-490.

15. Hung JW, Tsai MY, Yang BY, Chen JF. Maternal osteoporosis after prolonged magnesium sulfate tocolysis therapy: a case report. Arch Phys Med Rehabil. 2005;86(1):146149.

16. Greenleaf JE. Physiological responses to prolonged bed rest and fluid immersion in humans. J Appl Physiol Respir Environ Exerc Physiol. 1984;57(3):619-633. 